\title{
POLÍTICAS E PROGRAMAS DE FORMAÇÃO CONTINUADA NO BRASIL: CONDUÇÃO DE PRÁTICAS DE LEITURA E ESCRITA NAS SALAS DE ALFABETIZAÇÃO
}

\author{
POLITIQUES ET PROGRAMMES D'ÉDUCATION PERMANENTE AU \\ BRÉSIL: CONDUITE DE PRATIQUES DE LECTURE ET D'ÉCRITURE \\ DANS LES COURS D'ALPHABÉTISATION
}

\author{
Rodrigo da Silva Guedes ${ }^{1}$
}

\begin{abstract}
Resumo: O presente texto traça uma linha histórica das Políticas e Programas de Formação Continuada para professores alfabetizadores a partir da década de 80. Objetiva identificar os programas e as marcas didáticas que são indicadas para as práticas escolares, sobretudo, as táticas relacionadas à leitura e escrita, muito presentes no fazer dos professores alfabetizadores. Com o advento do Construtivismo na década de 80; a "Década da Alfabetização" e os programas de formação continuada para professores alfabetizadores: PCN's em Ação, PRALER, TRILHAS, PROFA, Letra e Vida, Ler e Escrever, Pró-Letramento, Pacto Nacional pela Alfabetização na Idade Certa, pudemos observar um direcionamento didático acerca das práticas realizadas pelos professores acerca da leitura e escrita em nosso país.
\end{abstract}

Palavras-chave: Formação Continuada; leitura; escrita; práticas.

Sommaire: Ce texte retrace une ligne historique des Politiques et Programmes de Formation Continue pour les alphabétiseurs des années 80 . Il vise à identifier les programmes et les notes didactiques qui sont indiqués pour les pratiques scolaires, notamment les tactiques liées à la lecture et à l'écriture, très présent dans l'enseignement des alphabétiseurs. Avec l'avènement du constructivisme dans les années 1980; la «Décennie de l'alphabétisation» et les programmes de formation continue des alphabétiseurs: PCN's in Action, PRALER, TRILHAS, PROFA, Letra e Vida, Reading and Writing, Pro-Literacy, National Pact for Literacy in the Right Age, nous avons pu observer une direction didactique sur les pratiques des enseignants sur la lecture et l'écriture dans notre pays.

Mots-clés: Formation Continue; lecture; écriture; pratiques.

\section{Introdução}

Iremos traçar uma breve linha histórica das políticas e alguns programas de formação continuada no período que corresponde de 1980 a 2013 no Brasil e no Estado de São Paulo.

Segundo Mortatti (2000), a década de 80 pode ser considerada um marco para as discussões sobre alfabetização e formação de professores, pois foi marcada pela vivência de uma escola com um ensino tradicional de alfabetização, em detrimento de uma escola, com práticas pedagógicas que deveriam se apropriar dos estudos sobre a Psicogênese da Língua Escrita, propostos por Ferreiro e Teberosky (1999), e que de alguma forma impactaram as práticas dos professores.

Brandão e Leal (2011) descrevem alguns percursos que a leitura e escrita tiveram, apontam três caminhos que delinearam os novos enfoques, dentre eles: a obrigação da alfabetização; $o$ letramento sem letras; e, ler e escrever com significado na Educação Infantil. Momentos que direcionaram as práticas, partindo de um olhar tradicional para ações respaldadas pelos estudos de

\footnotetext{
${ }^{1}$ Rede Pública Municipal - Mogi das Cruzes/SP.
} 
Ferreiro e Teberosky (1999). Ler e escrever com significado, o último caminho descrito pelas autoras, são apresentados por Brandão e Leal (2011) como um período: “inspirado, por um lado, nas ideias de Ferreiro e Teberosky sobre o processo de alfabetização, que começaram a ser divulgadas no Brasil, ao final da década de 1970, trazendo um grande impacto para as formas de pensar a alfabetização (...)". (BRANDÃO e LEAL, 2011, p. 19).

O percurso histórico abordado traça o perfil leitor ou até mesmo tático acerca das práticas de leitura que a escola foi se apropriando ao passo que as Políticas e Programas de Formação Continuada foram sendo conduzidos em nosso país.

\section{Formação continuada para os professores alfabetizadores}

\subsection{Políticas educacionais}

A repercussão do construtivismo no país teve significativas mudanças nas ações docentes como diagnóstico de leitura e escrita (cf. FRADE, 2010), concepção de avaliação e demais procedimentos didáticos para o ensino. O Estado de São Paulo, por exemplo, instituiu o construtivismo em suas linhas de atuação: formação continuada, materiais escritos, chegando à sala de aula com as práticas dos professores.

(...) o construtivismo passa a ser defendido pelos "educadores progressistas", que se empenham no convencimento dos alfabetizadores, mediante produção, tradução e divulgação massivas de artigos, teses acadêmicas, livros e vídeos de combate, cartilhas construtivistas, sugestões metodológicas e relatos de experiências bem sucedidas, visando a garantir sua institucionalização na rede pública de ensino. (MORTATTI, 2000, p. 27)

No Ciclo Básico, de acordo com Mortatti (2000), o eixo norteador de todas as ações foi o construtivismo, impulsionando a instalação de Oficinas Pedagógicas, cursos de aperfeiçoamento e "reciclagem", como ficaram conhecidos na época, e a consolidação dos Centros de Formação e Aperfeiçoamento do Magistério (CEFAM's).

A década de 80 foi significativa para o campo da alfabetização, assim como, para o processo histórico, social e de lutas, pelo qual o país estava passando. Mortatti (2000) traça uma linha histórica dos movimentos, lutas e discussões sobre esse período: "No momento em que as conquistas políticas conduzem à concretização da democracia, a escola democrática precisa tornar-se realidade" (PALMA FILHO, 1985, p. 4 apud. MORTATTI, 2000, p. 260).

Tais constatações são muito bem descritas por Mortatti (2000) ao abordar de maneira detalhada os impactos da década de 80 sobre as discussões da alfabetização, escola e formação de professores. A autora comenta que houve uma "revolução conceitual" (MORTATTI, 2000, p. 19) quando alude às rupturas entre o tradicional e a perspectiva psicológica, pontua que com tal acontecimento, desencadeou um aumento no campo das pesquisas, visto que as respostas daquele momento já não correspondiam mais aos questionamentos elaborados pelos professores e sociedade.

A década de 90 proporcionou grandes investimentos na pesquisa sobre a formação continuada dos professores, como podemos perceber nos estudos realizados por Frade (2010), Soares (2011), Mendes e Romanowski, Santos, Oliveira (2008), entre outros.

Em um primeiro momento podemos ilustrar a década de 90 pelo viés dos investimentos das agências internacionais (Banco Mundial e Fundo Monetário Internacional) que conduzem os recursos para as ações destinadas à educação do país (cf. OLIVEIRA, 2008). No segundo 
momento, destacamos a interferência da Lei de Diretrizes e Bases da Educação Nacional n9394/96, mediante a democratização do país no final da década de 80 .

Neste sentido, Oliveira (2008) esboça que as legislações promulgadas na década de 90 oportunizaram mudanças nos processos de formação continuada trazendo novas propostas e indicando outras tendências para compreensão das práticas pedagógicas. "Dos destaques feitos à LDB 9.394/96, vimos uma estruturação de proposta de formação docente, frente às novas demandas requeridas no trabalho dos professores e o enfoque nos órgãos responsáveis pela organização dessa formação, bem como seus objetivos." (OLIVEIRA, 2008, p. 38 e 39).

Convém reforçar que todas as ações sobre a formação continuada propostas pelas agências nacionais e internacionais, assim como os dispositivos legais convergem para que haja uma melhoria, ora nas práticas dos professores ora nos índices apresentados nas avaliações externas (cf. MENDES e ROMANOWSKI).

No período correspondente entre 2003 a 2012, vivenciamos a "Década da Alfabetização", cujo foco foi direcionado para ações (programas, políticas e pesquisas), que viessem a contribuir com as práticas pedagógicas resultando a melhoria progressiva das avaliações externas. Mortatti (2013) descreve esse cenário como um período marcado por diversas ações, analisando e problematizando o contexto escolar. O percurso histórico na área mostrou avanços teóricos - metodológicas discussões e reflexões presentes nas escolas, por meio das Políticas de Formação continuada para os professores alfabetizadores.

Ao longo desse período cronológico em que destacamos a formação continuada, pudemos acompanhar a transição das crianças de seis anos de idade, que até então frequentavam a Educação Infantil, irem para o Ensino Fundamental, com a ampliação do Ensino Fundamental de oito para nove anos, instituído pela Lei $\mathrm{n}^{\circ} 11.274$ de 06/02/2006, marcando a trajetória escolar, por meio de discussões sobre a concepção de criança, o papel do professor e as práticas pedagógicas para atender essa criança (cf. CHAGURI e JUNG 2013).

\subsection{Programas de Formação Continuada}

O Programa PCN's em Ação foi uma parceria entre o governo federal, estados e municípios, oportunizando a formação continuada dos professores das redes de ensino, tendo como estrutura, encontros em grupo de discussões em torno dos Parâmetros Curriculares, além de outras temáticas.

Após o período marcado pelos PCN's em Ação, o Ministério da Educação, apresenta e institui o Programa de Formação de Professores Alfabetizadores - PROFA (2001), que nos anos subsequentes é disseminado pelos Estados e Municípios, sobretudo pela rede estadual de São Paulo, que passa a utilizar a metodologia proposta pelo PROFA nas práticas dos professores.

$\mathrm{Na}$ formação do PROFA, os professores realizavam estudos, com o auxílio de cadernos orientadores, vídeos instrucionais e reflexivos, assim como planejavam e discutiam as ações pedagógicas realizadas nas classes de alfabetização, como se pode observar que "o Programa visa nortear o trabalho do professor, oferecendo-lhe os fundamentos que vão da identificação da sua concepção teórica até a sugestão de mudanças na sua ação alfabetizadora”. (CAMPOS, 2006, p. 37).

No ano de 2003, presenciamos o Programa de Apoio a Leitura e Escrita (PRALER), continuando os estudos no campo da alfabetização para os professores alfabetizadores a fim de "dinamizar o processo educacional relativo à aquisição e aprendizagem da leitura e escrita da língua materna" (BRITO e VIÉDES, 2015, p. 156).

O PRALER está embasado em três grandes ações: formação continuada do professor formador e do professor cursista, sistema de avaliação do programa e atividades de apoio à aprendizagem dos alunos. (BRASIL, 2007). Conseguimos perceber a inter-relação entre o 
processo formativo e as práticas a serem desenvolvidas em sala de aula. O programa buscou preservar a relação teoria e prática em suas ações (DIAS, 2011).

No Estado de São Paulo, o PROFA ganhou proporções maiores para o processo formativo, tendo uma nova "roupagem" - Letra e Vida (2007) e na sequência, com uma remodelagem nos materiais de formação e agregando recursos didáticos (livros textos, livros de atividades para os alunos, livros de literatura infantil), passa a ser conhecida e até hoje é disseminada na rede estadual de São Paulo como "Ler e Escrever".

Assim como outros programas de formação continuada mencionados, o Letra \& Vida prioriza o processo de ensino e aprendizagem ao redor da leitura e da escrita como podemos observar na exposição de Hernandes (2008, p. 46).

A metodologia de formação priorizada pelo Programa pretende alavancar a construção de competências profissionais que sirvam de ferramentas para que o alfabetizador tenha sucesso na sua tarefa de ensinar a ler e escrever em situações sociais de uso da linguagem escrita.

No ano de 2007, além da discussão do Letra \& Vida no Estado de São Paulo, os sinais formativos foram marcados pelo Pró - Letramento, ampliando e fortalecendo os tempos e espaços de discussão sobre o ciclo de alfabetização e seus saberes no espaço escolar. Nesse sentido, a reflexão, planejamento e desenvolvimento de práticas que pudessem atender as necessidades no processo de ensino e aprendizagem nas classes de alfabetização.

Gontijo (2014, p. 70) expõe que o Pró-Letramento "é um programa de formação de professores das séries iniciais do ensino fundamental e tem por objetivo a melhoria dos níveis de desempenho em leitura e escrita", ressalta o que já encontramos nos materiais do Programa, nos objetivos dos Centros de Pesquisa e Desenvolvimento da Educação, no PNE e nas exigências dos órgãos internacionais (ONU e UNESCO).

No ano de 2011, contribuindo com as ações formativas, o TRILHAS teve notoriedade ao compor esse caminho de formação continuada destinada aos professores alfabetizadores, tendo como objetivo melhorar as ações relacionadas com a linguagem oral e escrita dos alunos. No Caderno de Apresentação do Programa (BRASIL, 2011) encontramos expresso que o projeto fortaleceu as ações para melhoria das habilidades de leitura e escrita. Em 2012, a formação foi desenvolvida em municípios considerados prioritários ${ }^{2}$, conforme indicações do MEC, ou seja, escolas com as notas abaixo do IDEB.

Gontijo (2014) aborda que "o MEC passou a implementar uma série de ações que constituem a política da alfabetização" (GONTIJO, 2014, p. 67). A autora descreve em sequência as políticas implementadas e posteriormente dedica um capítulo para detalhar cada uma delas e como se articulam, desse modo, apresenta três situações fortemente difundidas:

$>$ Formação de professores alfabetizadores;

> Implantação do Ensino Fundamental para 9 anos;

$>$ Escolha do Livro Didático - PNLD.

Esses três eixos elencados pela autora, se mostram no cotidiano das escolas brasileiras, e nos programas de formação continuada, principalmente no Pró-Letramento e PNAIC, onde a formação continuada dos professores alfabetizadores relaciona-se com a estrutura formativa dos programas do Ministério da Educação e demais ações, como pro exemplo: Programa

\footnotetext{
2 No portal TRILHAS, conseguimos mapear os estados, municípios e as escolas atendidas pelo programa: http://www.portaltrilhas.org.br/escola-beneficiada.html.
} 
Nacional do Livro Didático - PNLD, Programa Nacional de Bibliotecas Escolares - PNBE, Avaliações externas, entre outros.

Em 2012, o Pacto Nacional pela Alfabetização na Idade Certa continuou com uma estrutura de formação muito próxima ao do Pró - Letramento, direcionadas aos professores alfabetizadores. Souza (2014) problematiza e aprofunda as concepções antecedentes sobre o Pacto para poder iniciar reflexões sobre a atual conjuntura da formação continuada.

\subsection{RENAFOR}

Dias (2011) traça um resumo das políticas de formação de professores, abordando sobre a Rede Nacional de Formação de Professores de Educação Básica, resgatando os objetivos propostos: "(Rede) foi proposta a partir do Edital n. 1, de 9 de junho de 2003, que tinha o objetivo de constituir centros de formação continuada, desenvolvimento da tecnologia e prestação de serviços para as redes públicas de ensino." (DIAS, 2011, p. 99). A RENAFOR foi efetivamente constituída em 2004 (BRASIL, 2006b, p. 3).

FRADE (2010b) ao pontuar sobre a formação continuada dos professores e o papel da RENAFOR na implementação de programas que vão ao encontro da prática pedagógica, esboça que, sobretudo, os programas pelos quais estamos apresentando:

(...) indica que não podemos mais denunciar a baixa oferta de formação contínua pelos órgãos oficiais, nem constatar que há uma única alternativa: há ações regulares e sistemáticas, alternativas de educação à distância e presencial, formações realizadas no âmbito das escolas e fora delas, atingindo professores leigos e com formação superior. (FRADE, 2010b, p. 44)

A articulação dos órgãos gestores dos sistemas de ensino, segundo o Ministério da Educação, contribui para os grandes investimentos na formação continuada dos professores, na qual cada agente (sistemas de ensino, órgãos gestores, universidades e instituições de formação) tornam-se responsável não somente pela formação continuada dos professores, assim como a melhoria na qualidade do ensino. (BRASIL, 2005)

Faz-se necessário pontuar, a importância que a RENAFOR tem para as práticas formativas, sobretudo para o surgimento dos programas de formação continuada para professores, visto que a $R E D E$, como ficou conhecida, possibilita a elaboração de materiais, cursos e subsídios das mais variadas formas (livros, textos, audiovisuais, pesquisas, cursos online, à distância, entre outros) possibilitando a reflexão das práticas pedagógicas dos professores (OLIVEIRA, 2008; DIAS, 2011).

Compreendemos que as ações não estão somente destinadas às ações formativas para os professores, mas amplia de maneira mais estruturada a articulação entre a academia e as unidades escolares vinculadas ao Ministério da Educação. Bunzen (2010) traz em seus escritos um olhar analítico para os discursos apresentados em materiais escritos para a formação de professores, e, contribui para uma elucidação sobre a Rede Nacional de Formação de professores, de modo que:

Para a Rede Nacional de Formação Continuada, a formação não deve ser vista como uma correção de um curso precário, uma vez que apostam na necessária reflexão permanente do professor. Por outro lado, os Centros de Pesquisa e Desenvolvimento da Educação encontra-se em instituições com tradições em ensino e pesquisa, situadas em diversas regiões do Brasil. Na área temática Alfabetização e Linguagem, nosso interesse de pesquisa, as universidades 
responsáveis pelos Centros de Pesquisa são: UFPE, UFMG, UNICAMP, UEPG, UNB. Os Centros, de forma geral, têm priorizado a produção de diversos materiais para os professores (jornais, sites, cadernos de estudo, vídeos), além dos materiais didáticos elaborados para o funcionamento dos cursos, com dinâmicas e formatos específicos. (BUNZEN, 2010, p. 5)

Os Centros mencionados poderiam ser compostos nas universidades com dedicação aos programas de formação continuada e intuito de prestar serviço às redes públicas de ensino, assim se constituíram como Centros de Pesquisa e Desenvolvimento da Educação. (DIAS, 2011). Deste modo, os Centros de Pesquisa e Desenvolvimento da Educação foram divididos em cinco grandes áreas do conhecimento: Alfabetização e Linguagem, Educação Matemática e Científica, Ensino de Ciências Humanas e Sociais, Artes e Educação Física, Gestão e Avaliação da Educação, conforme consta no catálogo (BRASIL, 2006b, p. 3).

No catálogo de 2005 encontramos expresso que "A Rede Nacional de Formação Continuada conta com a participação dos Centros de Pesquisa e Desenvolvimento da Educação, com os sistemas de ensino público e a participação e coordenação da SEB / MEC." (BRASIL, 2005, p. 22).

Os Centros de Pesquisa apresentam características históricas - sociais e de problematização, dentro da área a ser pesquisada, estabelecendo diálogos interinstitucionais, a fim de ampliar as pesquisas na área, com suas especificidades na construção do conhecimento, são vinculados a uma universidade com o intuito de produzir materiais didáticos, com um professor coordenador dos trabalhos e constituindo um comitê gestor (DIAS, 2011).

Iremos nos ater à Alfabetização e Linguagem, que está subdivida na seguinte conformidade:

\begin{tabular}{|c|c|c|}
\hline Universidade & Centro de Pesquisa & Professores Coordenadores \\
\hline $\begin{array}{l}\text { Universidade Federal de } \\
\text { Minas Gerais - UFMG }\end{array}$ & $\begin{array}{l}\text { Centro de Alfabetização, Leitura e Escrita - } \\
\text { CEALE }\end{array}$ & $\begin{array}{l}\text { Antônio Augusto Gomes Batista } \\
\text { Aparecida Paiva }\end{array}$ \\
\hline $\begin{array}{l}\text { Universidade Estadual de } \\
\text { Ponta Grossa - UEPG }\end{array}$ & $\begin{array}{l}\text { Centro de Formação Continuada, Desenvolvimento } \\
\text { de Tecnologia e Prestação de Serviços para as Redes } \\
\text { Públicas de Ensino - CEFORTEC }\end{array}$ & Cleide Aparecida Faria Rodrigues \\
\hline $\begin{array}{l}\text { Universidade Federal de } \\
\text { Pernambuco-UFPE }\end{array}$ & $\begin{array}{l}\text { Centro de Estudos em Educação e Linguagem - } \\
\text { CEEL }\end{array}$ & $\begin{array}{l}\text { Artur Gomes de Morais } \\
\text { Andrea Tereza Brito Ferreira } \\
\text { Eliana Borges C. de Albuquerque } \\
\text { Telma Ferraz Leal }\end{array}$ \\
\hline $\begin{array}{l}\text { Universidade de Brasília - } \\
\text { UNB }\end{array}$ & $\begin{array}{l}\text { Centro de Formação Continuada de Professores - } \\
\text { CEFORM }\end{array}$ & $\begin{array}{l}\text { Glória Pacita Fraguas Vásquez } \\
\text { Gomes }\end{array}$ \\
\hline $\begin{array}{l}\text { Universidade Estadual de } \\
\text { Campinas - UNICAMP }\end{array}$ & $\begin{array}{l}\text { Centro de Formação Continuada do Instituto de } \\
\text { Estudos da Linguagem - CEFIEL }\end{array}$ & Marilda do Couto Cavalcanti \\
\hline
\end{tabular}

Quadro 1 - Universidades e Centros de Pesquisa e Desenvolvimento da Educação - Fonte: MEC. Rede Nacional de Formação Continuada de Professores de Educação Básica - Orientações Gerais. Centros de Pesquisa e Desenvolvimento da Educação. SEB, 2006. (Quadro organizado pelo pesquisador).

O CEALE foi criado em $1999^{3}$, com o objetivo de integrar ações interinstitucionais nas áreas de alfabetização e ensino de Português, passando a integrar o RENAFOR, a partir de sua

\footnotetext{
${ }^{3}$ Disponível em: http://www.ceale.fae.ufmg.br/o-que-e-o-ceale.html.
} 
instituição, juntamente com os demais Centros de Pesquisa e Desenvolvimento em Educação. Dias (2011, p. 102) expõe que o CEALE “é um órgão complementar da Faculdade de Educação da UFMG, que, em 2004, passou a integrar a Rede, por meio do convênio com o MEC. Em 2010, completou vinte anos, reconhecidamente como uma das referências nacionais em estudo sobre alfabetização e letramento".

O CEFORTEC, em articulação com outras três Universidades Paranaenses: Unioeste, UEL e UFPR, objetiva:

\begin{abstract}
Apoiar os municípios no desenvolvimento de um plano permanente de desenvolvimento profissional dos docentes. Identificar áreas deficitárias do processo formativo que merecem maior atenção das entidades formadoras. "Contribuir com os sistemas municipais e estaduais de ensino no processo de formação continuada de professores na área de alfabetização e linguagem." (Disponível em: http://ead.uepg.br/site/programas-e-projetos/cefortec/).
\end{abstract}

O CEEL ${ }^{4}$ possui o foco na melhoria da Educação Básica, trabalhando especificamente com a organização e elaboração de cursos, planejamento e organização de propostas curriculares, avaliações de rede, produção de livros, vídeos e jogos didáticos, além de prestar assessoria a secretarias de educação e participar de programas de avaliação e produção de material didático e eventos científicos.

O CFORM 5 "foi concebido como um órgão multidisciplinar e supra-departamental da Universidade de Brasília (UNB)" (DIAS, 2011, p. 102). Os Departamentos da UNB articulados para compor o CFORM são: Núcleo de Estudos e Acompanhamento das Licenciaturas (NEAL) e o Centro de Estudos Avançados Multidisciplinares (CEAM) atua em duas grandes linhas de ação, apoiar os cursos de licenciaturas, sistematizar e ampliar a oferta de oportunidades de formação continuada de professores do ensino público.

O CEFIEL, assim como os demais centros de pesquisa, possui suas ações destinadas em contribuir com as ações para a formação continuada, para "pluralizar as formas de tornar parcelas mais amplas da sociedade beneficiárias da qualidade de seu ensino, pesquisa e extensão." (Disponível em: http://www.iel.unicamp.br/cefiel/apresentacao.php).

A RENAFOR estabelece relações entre os tempos e espaços que a formação continuada de professores adentra, posto que os programas que vieram em épocas posteriores, como Pró Letramento e Pacto Nacional pela Alfabetização na Idade Certa possuíam suas estruturas, concepções e princípios estabelecidos pelo Ministério da Educação em parceria com os Centros de Pesquisa e Desenvolvimento da Educação / RENAFOR.

\title{
3. Considerações
}

Nossa tentativa, propositalmente, compreendeu em traçar uma linha histórica das Políticas e Programas de Formação Continuada. As discussões advindas da década de 80; as implementações de políticas de formação nos anos 90; a "Década da Alfabetização"; os Centros de Pesquisas; foram marcas históricas presentes que contribuíram para a elaboração e desenvolvimento dos programas: Pró - Letramento e na sequência, do Pacto Nacional pela Alfabetização na Idade Certa.

\footnotetext{
${ }^{4}$ DIAS (2011), também disponível em: http://www.portalceel.com.br/apresentacao/\#ancora.

${ }^{5}$ Disponível em: http://wwwcform-formacao-unb.blogspot.com.br/2006/08/centro-de-formao-continuada-de.html.
} 

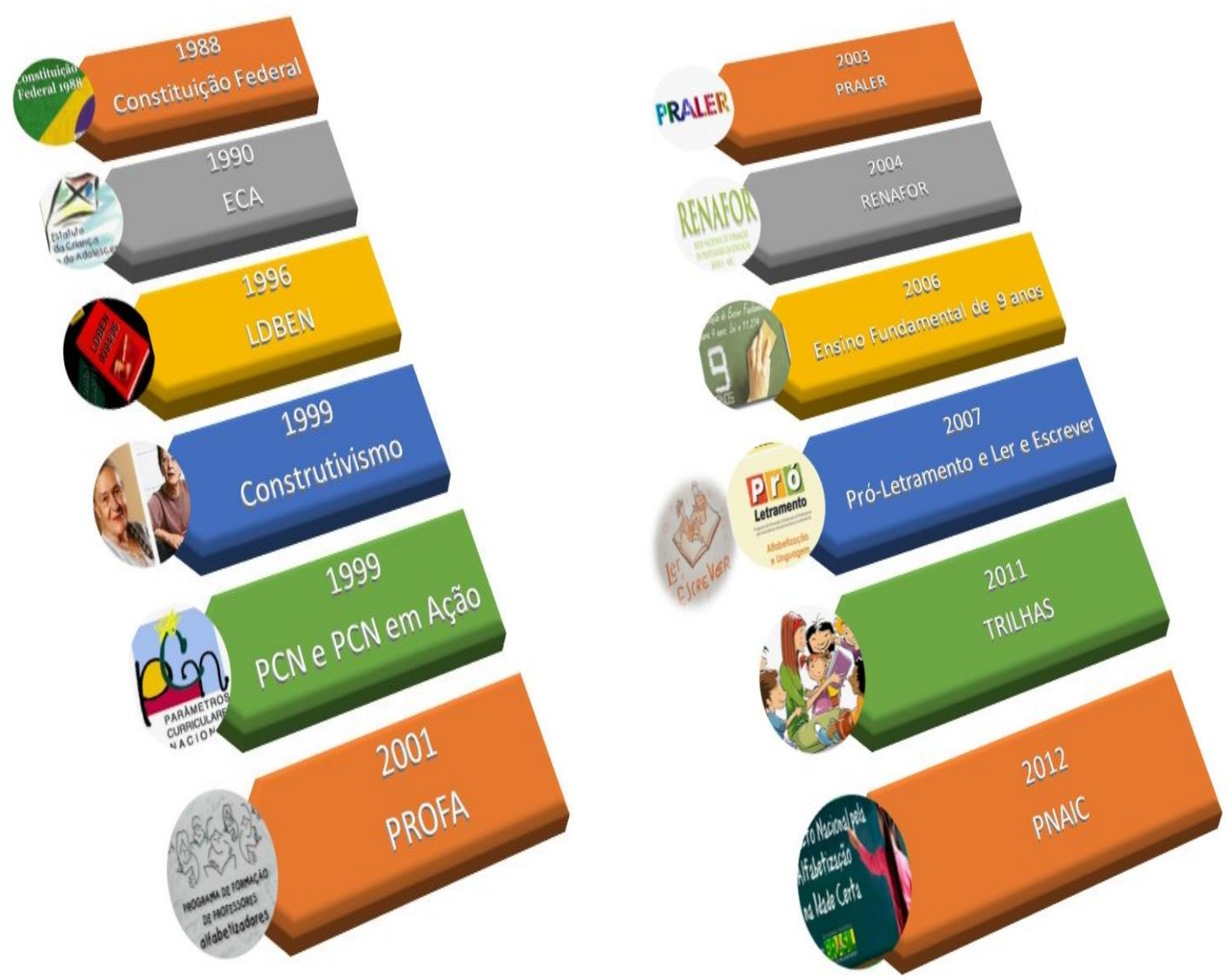

Ilustração 1 - Linha do Tempo 1988-2012 - Fonte: Ilustração elaborada pelo pesquisador.

Consideramos oportuno pontuar a importância que a formação continuada por meio dos programas passou a ter, obtendo proporções significativas na atuação dos professores alfabetizadores, pelo fato de observarmos que ao longo da história houve uma continuidade das ações destinadas para a formação continuada dos professores.

O processo histórico sobre a formação continuada, por meio dos programas elencados a partir da década de 80, contribui com nossos olhares investigativos e exploratórios para a compreensão de que os investimentos realizados nos/pelos programas de formação continuada direcionaram as práticas dos professores alfabetizadores, sobretudo no tratamento didático sobre leitura e escrita.

\section{Referências}

BRASIL. Rede Nacional de Formação Continuada de Professores de Educação Básica Orientações Gerais. SEB, 2005.

BRASIL. Lei $n^{\circ} 11.274$ de 06 de fevereiro de 2006. Altera a redação dos arts. 29, 30, 32 e 87 da Lei n 9394 de 20 de dezembro de 1996, que estabelece as diretrizes e bases da educação nacional, dispondo sobre a duração de 9 (nove) anos para o ensino fundamental, com matrícula obrigatória a partir dos 6 (seis) anos de idade. 2006.

BRASIL. Rede Nacional de Formação Continuada de Professores de Educação Básica Orientações Gerais. Centros de Pesquisa e Desenvolvimento da Educação. SEB, 2006. 
BRASIL. Programa de Apoio a Leitura e Escrita - PRALER. Guia geral. SEB, 2007.

BRASIL. Trilhas - Caderno de Apresentação. Ministério da Educação, São Paulo, 2011.

BRITO V. M.; VIÉDES, S. C. A. A. Política Educacional de alfabetização da criança consubstanciada pelos programas, projetos, e pactos: o novo ou tudo de novo? Revista HISTEDBR On-line, Campinas, n. 63, p. 147-171, jun. 2015.

BRANDÃO, A. C. P. LEAL, T. F. Alfabetizar e letrar na Educação Infantil: o que isso significa? In: BRANDÃO, A. C. P. ROSA, E. C. S. (Org.). Ler e Escrever na Educação Infantil: discutindo práticas pedagógicas. Belo Horizonte: Autêntica, 2011.

BUNZEN, C. Formação continuada: divulgação e didaticidade do conceito de letramento. In: BUNZEN, C. PIETRI, E. REVAH, D. VÓVIO, C. L. Dinâmicas entre universidade e escola pública: desafios do letramento para a formação de professores. Anais do XV ENDIPE, Belo Horizonte, 2010.

CAMPOS, R. G. M. O programa de formação de professores alfabetizadores - PROFA - e suas implicações pedagógicas: concepção de alfabetização, atuação profissional e resultados obtidos. Dissertação de Mestrado. Universidade Católica de Goiás, 2006.

CHAGURI, J. P.; JUNG, N. M. Letramento no ensino fundamental de nove anos no Brasil: ações legais e pedagógicas previstas nos documentos oficiais. Revista Educação e Pesquisa, São Paulo, v. 39, n. 4, p. 927-942, out./dez. 2013.

DIAS, P. M. C. R. Contribuições as sociolinguística educacional para materiais de formação continuada de professores de língua portuguesa. Tese de doutorado. Brasília, UNB, 2011.

FERREIRO, E. TEBEROSKY. A. Psicogênese da língua escrita. Porto Alegre: Artmed, 1999.

FRADE, I. C. A. S. Alfabetização e Letramento: convergências e tensões no campo da formação e do trabalho docente - apresentação. In: FRADE, I. C. A. S. Convergências e tensões no campo do trabalho docente. (Org.). Belo Horizonte: Autêntica, 2010.

FRADE, I. C. A. S. Formação de professores alfabetizadores no Brasil no contexto da Rede Nacional de Formação Continuada: produção, apropriações e efeitos. In: FRADE, I. C. A. S. Convergências e tensões no campo do trabalho docente. (Org.). Belo Horizonte: Autêntica, 2010b.

GONTIJO, C. M. M. Alfabetização: políticas mundiais e movimentos nacionais. Campinas: Autores Associados, 2014.

HERNANDES, E. D. K. Formação de professores alfabetizadores - efeitos do programa "Letra e Vida" em escolas da região de Assis. Tese de doutorado. UNESP, 2008.

MENDES, K. V. M.; ROMANOWSKI, J. P. Formação Continuada de professores: os modelos com base na racionalidade técnica. p. 2587-2595. 
MORTATTI, M. R. L. Os sentidos da alfabetização: (São Paulo / 1876-1994). São Paulo: Editora UNESP, 2000.

MORTATTI, M. R. L. Um balanço crítico da "Década da Alfabetização" no Brasil. In: Caderno CEDES, v. 33, n. 89, Campinas, jan./abr. 2013.

OLIVEIRA, M. A. V. Formação Continuada na escola pública e suas relações com a organização do trabalho docente. Dissertação de Mestrado. Universidade Federal de Minas Gerais, 2008.

SANTOS, E. O. Políticas de formação continuada para os professores da Educação Básica. p. 1-12.

SOARES, Magda. As muitas facetas da Alfabetização. In: SOARES, M. Alfabetização e Letramento. São Paulo: Contexto, 2011. p. 13-25.

SOUZA, E. E. P. S. A formação continuada do professor alfabetizador nos cadernos do Pacto Nacional pela Alfabetização na Idade Certa (PNAIC). Dissertação de Mestrado. UFSC, 2014.

\section{Sobre o autor}

Rodrigo da Silva Guedes. Doutorando em Educação pela UNICAMP, formado em Pedagogia pela UMC - Universidade de Mogi das Cruzes e Mestre em Educação pela Universidade Federal de São Paulo - UNIFESP. Atua no magistério público como professor de Educação Básica (Infantil e Fundamental), atualmente na função de Vice-Diretor de escola pública no município de Mogi das Cruzes/SP. Pesquisa direcionada para as práticas pedagógicas, formação continuada de professores e alfabetização.

E-mail: rodrigoguedes2005@yahoo.com.br. 